RESIDENT

\& FELLOW

SECTION

Section Editor

Mitchell S.V. Elkind,

MD, MS

Kerri L. LaRovere, MD

James J. Riviello, Jr., MD

Address correspondence and reprint requests to Dr. Kerri L. LaRovere, Children's Hospital Boston, Department of Neurology, Fegan 11, 300 Longwood Avenue, Boston, MA 02115

kerri.larovere@childrens. harvard.edu

\title{
Emerging Subspecialties in Neurology: Building a career and a field
}

Pediatric neurocritical care

The specialty of neurocritical care (NCC) has evolved rapidly and has an exciting future. The current neurologic intensive care units (NICUs) were born in the 1960s as a collaborative effort among the various subspecialists caring for patients with neurologic illnesses in multidisciplinary intensive care units (ICUs). The first dedicated NICUs appeared in the mid-1970s, and training programs soon followed. There are now 50 dedicated NICUs run by fellowship-trained neurointensivists in 29 states, and 15 hospitals in which neurointensivists provide consultant services. ${ }^{1}$ Dedicated NICUs have permitted many advances in basic science, diagnostic, monitoring, and therapeutic techniques in NCC.

Neurointensivists apply the basic principles of neuroresuscitation, the ABCs (airway, breathing, and circulation/cerebral blood flow), to the management of acute, life-threatening brain and spinal cord insults or "failure." Common diagnoses in the adult NICU include postoperative tumor, stroke, subarachnoid hemorrhage, traumatic brain injury, and intracerebral hemorrhage. Successful management depends upon properly diagnosing, monitoring, and treating these conditions, as well as upon preventing and treating any secondary complications, namely disturbances of cerebral perfusion and intracranial pressure. The clinical and scientific progress in this new specialty has spawned the international Neurocritical Care Society; a peer-reviewed scientific journal, Neurocritical Care; and the approval of NCC for subspecialty certification by an independent, nonprofit professional medical organization, the United Council for Neurologic Subspecialties (UCNS). The next step is certification by the Accreditation Council for Graduate Medical Education, which will signify general acceptance of NCC.

We were drawn to pediatric NCC during our pediatric neurology training because of an interest in managing acute neurologic insults. More- over, NCC is a new frontier in clinical child neurology with unlimited opportunities for research. Recent collaborative efforts have produced several evidence-based guidelines for the field. In 2000, a working group assembled by the International Brain Injury Association created guidelines for severe pediatric head trauma, ${ }^{2}$ with the hope that standardized management of pediatric traumatic brain injury will allow outcome analyses intended to improve current therapies. Guidelines from the United States and United Kingdom have been developed for arterial ischemic stroke and cerebral sinovenous thrombosis in children, ${ }^{3,4}$ and the International Pediatric Stroke Study has created an international stroke registry in an effort to develop true evidencebased practice standards and perform future clinical trials. In addition, the American Academy of Neurology and Child Neurology Society developed a practice parameter for the Diagnostic Assessment of the Child with Status Epilepticus. ${ }^{5}$

As in adult NCC, additional pediatric research topics include age-specific and disease-specific studies related to measurements of cerebral blood flow and intracranial pressure; determinations of clinical, biologic, neurophysiologic, radiologic, and pathologic markers of CNS injury; therapeutic effects on outcome; and factors important in recovery of function. Unlike that of adult NCC, the research agenda in children has a critical additional layer: understanding the response of the developing brain to acute and severe CNS injury. However, pediatric NCC lags behind adult NCC. The field of pediatric neurology does not yet have dedicated pediatric NICUs or training programs, and to date, pediatric NCC has been driven forward by work that has "trickled down" from adult NICUs or from neonatal neurology.

In the current practice of pediatric NCC, the pediatric neurologist functions as a consultant to the pediatric ICU (PICU) team in the evaluation and treatment of acute ischemic stroke, intracere- 
bral hemorrhage, traumatic brain injury, anoxic brain injury, status epilepticus, CNS infections, autoimmune and postinfectious disorders, neuromuscular emergencies, neurometabolic crises, postoperative CNS tumors and epilepsy surgery, neurologic complications of general medical and surgical illnesses, and brain death. A multidisciplinary approach is needed to best care for these children. The pediatric neurologist is needed in the PICU as an expert in the neurologic history and examination of a child, an invaluable skill necessary for decision-making and determining prognostic variables. Furthermore, PICUs need the pediatric neurologist because many of the neurologic disorders of these children are chronic, unlike those of their adult counterparts. ${ }^{6,7}$ A pediatric neurologist on the PICU team will provide the best neurologic care for these children.

To establish this frontier, the Department of Neurology at Children's Hospital Boston, under Dr. Joseph Volpe, created a dedicated critical care neurology service in 1996. All neurology consultations in the medical/surgical PICU, the cardiac intensive care unit, and three neonatal intensive care units are performed by a dedicated critical care neurology team distinct from the inpatient neurology consult team. This service was created because it became difficult for a general neurology consult service to incorporate the many advances in neonatal neurology and NCC into clinical practice. In 2006, this service provided 557 new consults and 3,539 follow-up consultations. Our group includes pediatric neurologists specializing in epilepsy and in neurovascular, neuromuscular, behavioral, and neonatal neurology, but only one had an anesthesiology background. We believe that in order to move our field forward in a manner similar to that of our adult counterparts, we now need to train dedicated pediatric NCC specialists. Presently, the Neurocritical Care Society is planning a workforce evaluation for pediatric NCC, which will be important for developing the field and for identifying funding strategies for training programs.

Several models of pediatric NCC delivery are possible. The most common model is an inpatient neurology consult service providing neurologic consultations to all inpatients. An alternative is the current Boston model, where a dedicated group of neurologists work as consultants to the PICU team. This requires a large neurology department or division. The ultimate model is the creation of a dedicated pediatric NICU staffed with NCC-trained pediatric neurologists, similar to the adult situation. However, the staff at our institution currently does not have the training, experience, or support personnel needed to function as primary attending physicians in a pediatric NICU. Given the current practice of pediatric critical care medicine, where the PICUs in major children's hospitals are closed units staffed by pediatric critical care medicine specialists, pediatric neurologists will most likely remain as consultants to this group. We believe that the best care ultimately will be delivered in a dedicated pediatric NICU staffed by a team consisting of pediatric intensivists and pediatric neurointensivists. In any model, evidence-based treatment guidelines are needed to standardize care and evaluate outcomes.

We believe it is time to move away from recruiting child neurology subspecialists who have a critical care interest to the NCC team, and instead to develop properly trained pediatric NCC subspecialists. The dedicated pediatric neurointensivist would be a member of the PICU team and help perform research on neurologic disorders in the PICU. This model should lead to increased educational efforts in neurointensive and non-neurointensive care, effective collaboration with other caregivers in the ICU, and more efficient care for children with critical neurologic illnesses. Collaboration with other neurologic subspecialists on the NCC team would continue, since epilepsy, neurovascular, and neuromuscular disorders are frequently seen in the ICU. ${ }^{8}$

The pediatric neurointensivist should have training and knowledge beyond pediatric neurology residency. In accordance with the UCNS guidelines for fellowship program requirements (http://www.ucns.org/accreditation), fellows must complete 12 months of on-service critical care training involving the direct diagnosis and management of critically ill neurologic patients, and 12 months of various non-critical care clinical rotations. For pediatric NCC, membership on a team in a medical/surgical PICU, pediatric cardiac intensive care unit, postanesthesia care unit, and adult NICU may count toward the 12-month on-service critical care requirement. Possible noncritical care electives include pediatric neurovascular or stroke service, epilepsy, neurosurgery, emergency department, interventional/diagnostic neuroradiology, Doppler lab, clinical neurophysiology, and research. In particular, training in applications and interpretation of pediatric EEG, continuous EEG, and neuroimaging and neuromonitoring devices including transcranial Doppler would be useful.

Foundations for a good pediatric NCC program include emphasis on general and neurologic 
intensive care through exposure to adult and pediatric general and neurologic ICUs in institutions with interested colleagues and opportunities for clinical and laboratory research. A committee of clinical and research mentors from pediatric neurology, as well as from all parent specialties in critical care medicine, anesthesiology, adult NCC, and neurosurgery, are paramount to future success. Institutions with well-developed ICUs and robust neurology services should consider devising a program. Post-residency (pediatric neurology or anesthesiology) training programs could consider fellowship training integrated with general and neurologic PICU and adult NICU/vascular neurology. Another possibility may be cross training of pediatric NICU specialists during residency with an effort to follow fellowship or practice track pathways (http://www. ucns.org/certification/requirements/\#neuroint) so that eligibility for the NCC certifying examination is possible.

The Department of Neurology at Children's Hospital Boston, under Dr. Scott Pomeroy, has established a pediatric NCC fellowship training program in conjunction with the adult vascular and NCC program at Massachusetts General Hospital/Brigham and Women's Hospital and the anesthesia/pediatric critical care program at Children's Hospital Boston. To our knowledge, this is the first and only such program in existence. The first year is a mixture of electives and service time in adult NCC with overnight adult NCC and stroke call. The second year consists of service time in pediatric critical care with rotations in anesthesia, cardiac intensive care, and PICU, and various pediatric non-critical care electives. These 2 years are structured according to the practice track pathway put forth by the UCNS. This program is funded by the Neurology Department in recognition of the need to provide this service to the many children we care for with acute and severe neurologic conditions, as well as the need to train future pediatric neurointensivists. Perhaps other major children's hospitals will recognize these needs as well, and create similar training programs.

Fellowship directories in NCC can be found on the UCNS Web site at http://www.ucns.org as well as through the American Academy of Neurology at http://www.aan.com/education/ fellowships. A list of pediatric critical care medicine fellowships is available on the pediatric critical care Web site at http://pedsccm.org. Fel- lowship funding may be difficult to find. Funds or grants to consider include those available from the government (http://www.grants.gov), such as the National Institute of Neurological Disorders and Stroke (http://www.ninds.nih.gov) and the National Institute of Child Health and Human development (http://www.nichd.nih.gov). Other funding sources may come from major professional organizations such as the Child Neurology Foundation (http://www.childneurologyfoundation.org), American Neurological Association (http://www. aneuroa.org), Association of University Professors of Neurology (http://www.aupn.org), Pediatric Critical Care Medicine, and the American Academy of Pediatrics (http://www.aap.org).

\section{ACKNOWLEDGMENT}

Dr. LaRovere thanks Dr. Allan Ropper for his comments on the initial manuscript. The authors also thank Shaye Moore for her assistance in preparing the manuscript.

\section{REFERENCES}

1. Wright WL. Putting neurocritical care units on the map. Currents 2007;2:4.

2. Adelson PD, Bratton SL, Carney NA, et al. Guidelines for the acute medical management of severe traumatic brain injury in infants, children, and adolescents. Pediatr Crit Care Med 2003;4(3 suppl):S1-S75 .

3. Monagle P, Chan A, Massicotte P, Chalmers E, Michelson AD. Antithrombotic therapy in children: The Seventh ACCP Conference on Antithrombotic and Thrombolytic Therapy. Chest 2004;126:645S-687S.

4. Paediatric Stroke Working Group. Stroke in childhood: clinical guidelines for diagnosis, management and rehabilitation [online]. Available at: http://www. rcplondon.ac.uk/pubs/books/childstroke. Accessed December 12, 2007.

5. Riviello JJ Jr, Ashwal S, Hirtz D, et al. Practice parameter: diagnostic assessment of the child with status epilepticus (an evidence-based review): Report of the Quality Standards Subcommittee of the American Academy of Neurology and the Practice Committee of the Child Neurology Society. Neurology 2006;67:15421550.

6. Dosa NP, Boeing NM, Ms N, Kanter RK. Excess risk of severe acute illness in children with chronic health conditions. Pediatrics 2001;107:499-504.

7. Graham RJ, Dumas HM, O’Brien JE, Burns JP. Congenital neurodevelopmental diagnoses and an intensive care unit: defining a population. Pediatr Crit Care Med 2004;5:321-328.

8. Pisón JL, Manso MG, Morales LR, Belloc SJ, Amez AF, Gimeno JM. Analisis descriptivo de la patologia neurologica en una unidad de cuidados intensivos pediatricos de referencia regional [Descriptive analysis of neurological disorders in the pediatric intensive care unit of a regional reference hospital]. An Esp Pediatr 2000;53:119-124 


\section{Neurology}

\section{Emerging Subspecialties in Neurology: Building a career and a field: Pediatric neurocritical care}

Kerri L. LaRovere and James J. Riviello, Jr

Neurology 2008;70;e89-e91

DOI 10.1212/01.wnl.0000313379.57609.25

\section{This information is current as of May 27, 2008}

\section{Updated Information \& Services}

References

Citations

Subspecialty Collections

Permissions \& Licensing

Reprints including high resolution figures, can be found at: http://n.neurology.org/content/70/22/e89.full

This article cites 7 articles, 1 of which you can access for free at: http://n.neurology.org/content/70/22/e89.full\#ref-list-1

This article has been cited by 1 HighWire-hosted articles: http://n.neurology.org/content/70/22/e89.full\#\#otherarticles

This article, along with others on similar topics, appears in the following collection(s):

All Pediatric

http://n.neurology.org/cgi/collection/all_pediatric

Information about reproducing this article in parts (figures,tables) or in its entirety can be found online at:

http://www.neurology.org/about/about_the_journal\#permissions

Information about ordering reprints can be found online:

http://n.neurology.org/subscribers/advertise

Neurology ${ }^{\circledR}$ is the official journal of the American Academy of Neurology. Published continuously since 1951, it is now a weekly with 48 issues per year. Copyright . All rights reserved. Print ISSN: 0028-3878. Online ISSN: 1526-632X.

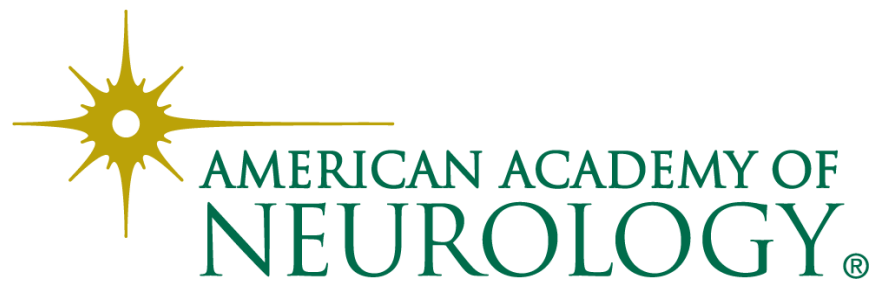

